\title{
Analysis of Voltage Support by Electric Vehicles and Photovoltaic in a Real Danish Low Voltage Network
}

Knezovic, Katarina; Marinelli, Mattia; Juul Møller, René ; Andersen, Peter Bach; Træholt, Chresten; Sossan, Fabrizio

\section{Published in:}

Proceedings of International Universities' Power Engineering Conference (UPEC) 2014

Link to article, DOI:

10.1109/UPEC.2014.6934759

Publication date:

2014

Link back to DTU Orbit

Citation (APA):

Knezovic, K., Marinelli, M., Juul Møller, R., Andersen, P. B., Træholt, C., \& Sossan, F. (2014). Analysis of Voltage Support by Electric Vehicles and Photovoltaic in a Real Danish Low Voltage Network. In Proceedings of International Universities' Power Engineering Conference (UPEC) 2014 IEEE.

https://doi.org/10.1109/UPEC.2014.6934759

\section{General rights}

Copyright and moral rights for the publications made accessible in the public portal are retained by the authors and/or other copyright owners and it is a condition of accessing publications that users recognise and abide by the legal requirements associated with these rights.

- Users may download and print one copy of any publication from the public portal for the purpose of private study or research.

- You may not further distribute the material or use it for any profit-making activity or commercial gain

- You may freely distribute the URL identifying the publication in the public portal 


\title{
Analysis of Voltage Support by Electric Vehicles and Photovoltaic in a Real Danish Low Voltage Network
}

\author{
Katarina Knezović, Mattia Marinelli, René Juul Møller, Peter Bach Andersen, Chresten Træholt, Fabrizio Sossan \\ Department of Electrical Engineering (Center for Electric Power and Energy), DTU - Technical University of Denmark \\ Contact Person: Katarina Knezović, kknez@elektro.dtu.dk
}

\begin{abstract}
With conventional generating units being replaced by renewable sources which are not required to provide same high level of ancillary services, there is an increasing need for additional resources to achieve certain standards regarding frequency and voltage. This paper investigates the potential of incorporating electric vehicles (EVs) in a low voltage distribution network with high penetration of photovoltaic installations (PVs), and focuses on analysing potential voltage support functions from EVs and PVs. In addition, the paper evaluates the benefits that reactive power control may provide with addressing the issues regarding voltage control at the expense of increased loading. Analysed real Danish low voltage network has been modelled in Matlab SimPowerSystems and is based on consumption and PV production data measured individually for number of households.
\end{abstract}

Index Terms--distribution network, electric vehicles, photovoltaic, power system modelling, voltage control

\section{INTRODUCTION}

Electrical power system is operated in order to follow the continually changing load demand with the minimum ecological impact and at minimum cost. In addition, the quality of power supply must meet certain standards regarding frequency and voltage, which are usually achieved through ancillary services provided to the system operator by other market participants. Due to independent liberalization of electricity sectors in different jurisdictions, technical features of these services vary considerably [1].

Today, conventional generating units are being replaced by renewable resources which are not required to provide the same high level of ancillary services. Increasing number of photovoltaic installations (PVs) influences residential energy consumption profiles causing voltage gradients in the distribution network [2], [3], especially in the areas where dense clusters have appeared [4]. Low electricity demand usually coincides with high power injections from PVs resulting in voltage rise issues and disabling greater integration of distributed resources. Hence, modern solar inverters typically have the capability of supplying or absorbing reactive power in times when active power flow is less than inverter's rated power [5].

On the other hand, electric vehicles (EVs) are a viable alternative to traditional vehicles and can be used for

This work is supported by the Danish Project - Nikola - under ForskEL kontrakt nr. 2013-1-12088. mitigating adverse effects of distributed renewable energy resources. A moderate penetration scenario from Danish Energy Association estimates 47,000 EVs will be present in Denmark by 2020 [5]. Comparing such a prediction to 1,400 EVs registered in January 2013, it is anticipated that EVs will have a great impact on the network consumption in the near future. However, EVs should not be considered as merely passive loads additionally stressing the network, but as distributed energy storage systems with great potential for network regulation. Since they are typically plugged-in $90 \%$ of the time, they are capable of providing different ancillary services for supporting the power grid, such as primary frequency control or voltage control [7]-[9]. Development of Vehicle-to-Grid technology will, among other things, enable EVs to provide voltage support functions similar to the ones from solar inverters.

This paper investigates the potential of incorporating EVs in a real Danish low voltage distribution network and focuses on analysing potential reactive power support by PVs and EVs. Furthermore, it evaluates the benefits that reactive power control may provide to the grid with addressing the issues regarding voltage control at the expense of increased loading. As the model represents a real low voltage network, this work may be used as a practical tool for the distribution system operator (DSO) in assessing PV and EV impacts on their low voltage grid.

\section{METHODOLOGY}

\section{A. Low voltage grid}

The analysed Danish low voltage network has been modelled in the software Matlab SimPowerSystems which uses graphical modelling with built-in common power grid components, and can easily be extended with arbitrary modelled ones. The observed low voltage feeder has been connected to the medium voltage grid represented by a $10 \mathrm{kV}$ three-phase voltage source with in series with a RL branch. As this is the only feeding point of the grid, the voltage source is assumed to be a swing generator with three-phase short circuit power of $20 \mathrm{MVA}$. The MV/LV transformer is modelled as a typical distribution transformer used in Danish low voltage networks: a $400 \mathrm{kVA}$ transformer with nominal ratio of $10.5 / 0.42 \mathrm{kV}$, and resistance and leakage inductance of each winding set to 0.005 p.u. and 0.02 p.u. respectively. 
The secondary star point winding of the transformer has been directly grounded.

The low voltage feeder is a line which bifurcates into three parts coinciding with physical streets where the households are located, and is run in radial configuration. The line consists of 14 nodes and 13 line segments with total length of 681 meters. All segments are the same type of $4 \times 150 \mathrm{~mm}^{2} \mathrm{Al}$ PEX conductor with $\mathrm{R}=0.207 \Omega / \mathrm{km}$ and $\mathrm{X}=0.078 \Omega / \mathrm{km}$. The single phase configuration of the described low-voltage network is given in Fig. 1. Part A represents 17 houses located in Hørmarken Street while part B represents 26 households located in Græsmarken Street. Households with PV installations and EVs are marked green, while the ones without PV are blue. In addition, there is a street light connected to the grid in Græsmarken Street at node 608 which is marked black.

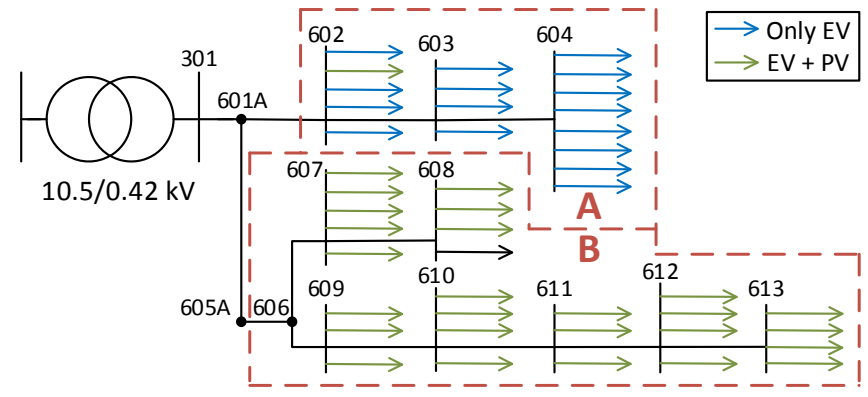

Fig. 1. Single phase diagram of modelled real Danish low voltage network

\section{B. Household consumption}

There are 43 households in total which can be divided in two categories due to their similar characteristics: (1) residential houses in Hørmarken Street, and (2) residential houses in Græsmarken Street. The first group has somewhat lower consumption profile during the heating season as a result of implemented district heating. Furthermore, none of the houses in this group have a PV installation except of one located at node 602. The second group covers households with PV installations, as well as with heat pumps and consequently higher consumption during heating season.

Consumption profiles are based on real metering data read on hourly basis through a period of one year (from March 2012 until March 2013). However, measured power flows are three-phased with no insight into shares of individual phases. Therefore, it is assumed that the loading is equally distributed and symmetrically balanced between the phases. Moreover, there are no data for the reactive power component, so the minimum required power factor has been taken as the reference value for all households $(\cos \varphi=0.95[10])$.

Since this paper focuses on voltage support in steady-state, the two most interesting weeks in the given year have been chosen for further analysis: (1) a spring week with low consumption and high PV production, and (2) a winter week with high consumption and almost no PV production. Fig. 2 shows total weekly consumption and average daily profile per house for the observed spring week. The later was calculated as a mean of all household consumptions at each hour of the

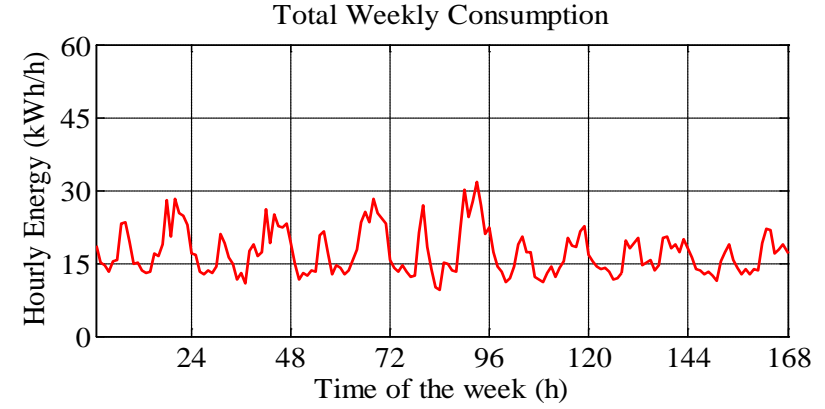

Average Daily Consumption

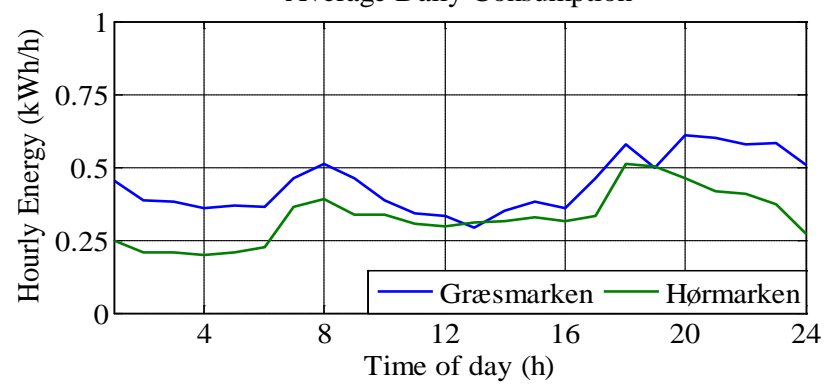

Fig. 2. Total weekly and average daily consumption per house for the observed spring week

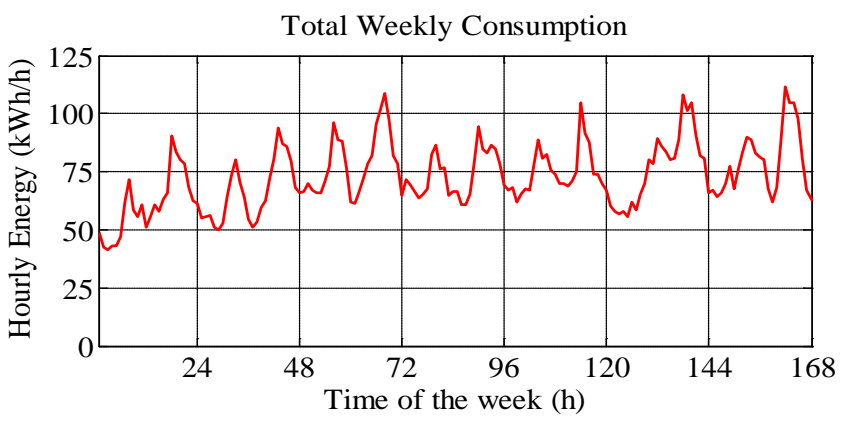

Average Daily Consumption

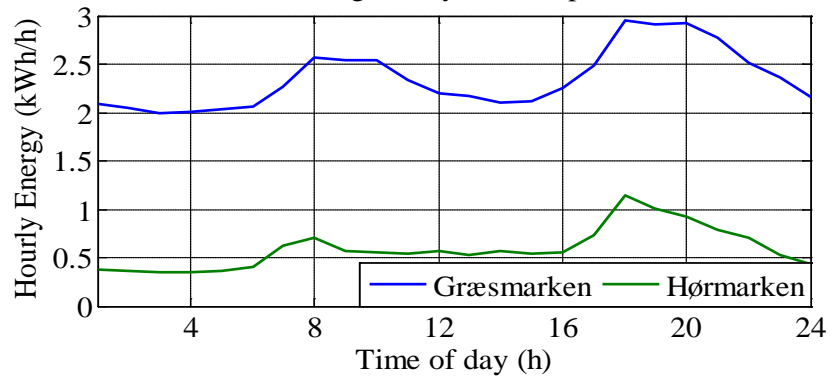

Fig. 3. Total weekly and average daily consumption per house for the observed winter week

day, separately for Hørmarken and Græsmarken. Similarly, Fig. 3 presents total consumption and average daily profile per house for the chosen winter week. It is clear that Græsmarken households have bigger consumption in the winter week as already mentioned, while the consumptions during the spring week are similar for both household groups.

Besides the modelled feeder, there are additional three feeders with number of houses under the same transformer substation. However, the data for these feeders are not available and thus, they are not modelled in this paper. When analysing the results, one has to bear in mind there is an additional load which will lower the voltage levels at the substation level more than in the simulated scenarios. 


\section{Photovoltaic installations with reactive power control}

PV installations are mostly located in Græsmarken (only one located in Hørmarken) and all of them are connected through single-phase inverters. Modelled network contains 27 PV installations in total: 24 installations with peak power $\mathrm{P}=2.96 \mathrm{~kW}_{\mathrm{p}}$ and 3 upgraded installations with $\mathrm{P}=4.07 \mathrm{~kW}_{\mathrm{p}}$, which are respectively connected through $3.6 \mathrm{~kW}_{\mathrm{p}}$ and 5.4 $\mathrm{kW}_{\mathrm{p}}$ inverters. The number of PVs connected to a particular phase is not known, so the installations have been connected randomly taking into consideration that the overall production on each phase should be approximately the same. The PV production has been measured separately for every house also on hourly basis along with the consumption data. Total weekly and average daily production values for the observed weeks have been summarised in Table I. Similarly to the average daily consumption, the average daily production is calculated as the mean of all PV productions at each hour which have then been summed up for the 24 hour period.

TABLE I

PV PRODUCTION FOR OBSERVED WEEKS

\begin{tabular}{|c|c|c|}
\hline & $\begin{array}{c}\text { Total weekly PV } \\
\text { production }(\mathrm{kWh})\end{array}$ & $\begin{array}{c}\text { Average daily production } \\
\text { per PV (kWh) }\end{array}$ \\
\hline Spring week & 3096.20 & 17.01 \\
\hline Winter week & 32.07 & 0.18 \\
\hline
\end{tabular}

PV installations are connected through single-phase inverters equipped with reactive power control (RPC) related to voltage level and produced active power. Voltage control specifications regarding overvoltage and undervoltage limits are chosen according to the Danish technical regulation for generation facilities with rated current $16 \mathrm{~A}$ per phase or lower [9]. According to the regulation, voltage limits are set to $\pm 10 \% U_{n}$, i.e. $U_{\min }=0.9$ p.u. and $U_{\max }=1.1$ p.u. However, all the specifications required for RPC are not determined by this regulation, thus the function of the controller has been modified according to technical rules for low voltage active users recommended by the Italian technical standards [11] which provide rules for both passive and active users. These standards set different requirements on the reactive power production by the PV inverter greater than $3 \mathrm{~kW}$ and define several variations depending on the size of the plant together with specific DSO-users agreements. The main objective of this control is voltage lowering by reactive inductive power injection whenever the PV is producing high amount of power. The voltage rises may be particularly sensible if the PV is localized in weak feeders or feeders with high density of other active sources. Since both Italy and part of Denmark belong to the same synchronous region, it is reasonable to expect that future Danish requirements will experience harmonization with other European regulations.

In this paper the application of mentioned technical rules is extended to EV charger. Since an EV charger with V2G capability could in principle allow both charge and discharge, it also includes the possibility to inject both reactive inductive power and reactive capacitive power for sustaining voltage drops. The implemented RPC capability from PVs is depicted in Fig. 4 and has already been used in [12] for studying a real Italian medium voltage network with high penetration of small-size PV plants. The green area between $0.99 \mathrm{U}_{\mathrm{n}}$ and $1.01 \mathrm{U}_{\mathrm{n}}$ can be interpreted as a dead band with no RPC regardless how the produced active power changes. The blue area represents operation in overvoltage conditions when the inverter consumes reactive power up to 0.5 p.u. in order to lower the voltages. Likewise, the inverter injects up to 0.5 . p.u. of reactive power when operation conditions are in the red undervoltage area.

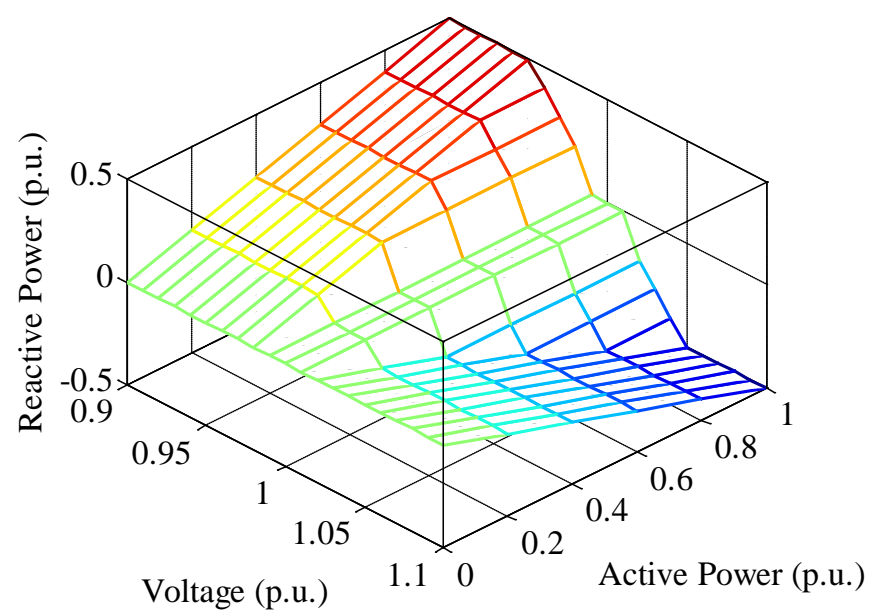

Fig. 4. Reactive Power Control capability for the PV inverters

\section{Electric vehicles}

Each of the 43 houses is equipped with a full electric vehicle whose charger has reactive power control resembling to the one of the PV inverters (just opposite in terms of injecting/consuming reactive power). The charging pattern of the vehicles has been taken from Test-en-EV program where real charging data were collected from 184 EVs spread around 10 Danish cities [13]. The charging starts immediately after the vehicle is connected with average charging time of 5 hours and total consumed energy of $14.3 \mathrm{kWh}$, which corresponds to the so called "dumb charging". This can be seen as the worst case scenario which could happen in the existing grid where there are no new reinforcements and the EV charging coincides with the critical peak time. The charging process starts at 6 p.m. with drawn power of $3 \mathrm{~kW}$ in the first hour followed by three hours of charging at nominal power of $3.7 \mathrm{~kW}$ and ending with only $0.2 \mathrm{~kW}$ in the last charging hour. Since EVs are connected to a single phase as well as the PVs, connection points were also randomly taken with overall even distribution on the phases and additional condition that the EV cannot be connected to the same phase as the PV installation.

This paper compares relevant network parameters between different scenarios, such as voltage values at the end of the lines and energy losses. Several steady-state analyses have been carried out depending on the observed week and combinations of available RPC from PVs and EVs. The differences between the scenarios have been described in Table II. 
TABLE II

SUMMARIZED DETAILS OF DIFFERENT CONDUCTED SCENARIOS

\begin{tabular}{|c|c|c|c|}
\hline Scenario & Season & PV status & EV status \\
\hline 1 & Spring & $\begin{array}{c}\text { All connected without } \\
\text { RPC }\end{array}$ & $\begin{array}{c}\text { All connected without } \\
\text { RPC }\end{array}$ \\
\hline 2 & Winter & $\begin{array}{c}\text { All connected without } \\
\text { RPC }\end{array}$ & $\begin{array}{c}\text { All connected without } \\
\text { RPC }\end{array}$ \\
\hline 3 & Spring & $\begin{array}{c}\text { All connected with } \\
\text { RPC }\end{array}$ & $\begin{array}{c}\text { All connected without } \\
\text { RPC }\end{array}$ \\
\hline 4 & Winter & $\begin{array}{c}\text { All connected with } \\
\text { RPC }\end{array}$ & $\begin{array}{c}\text { All connected without } \\
\text { RPC }\end{array}$ \\
\hline 5 & Spring & $\begin{array}{c}\text { All connected with } \\
\text { RPC }\end{array}$ & $\begin{array}{c}\text { All connected with } \\
\text { RPC }\end{array}$ \\
\hline 6 & Winter & $\begin{array}{c}\text { All connected with } \\
\text { RPC }\end{array}$ & $\begin{array}{c}\text { All connected with } \\
\text { RPC }\end{array}$ \\
\hline
\end{tabular}

\section{RESULTS AND DISCUSSION}

\section{A. Base scenarios (scenarios \#1 and \#2)}

As it is assumed that the consumption is equally divided on three phases as well that PVs and EVs are evenly distributed between the phases, all presented results depict the single phase states. Moreover, most of the results will be shown using boxplots - descriptive statistical method which graphically depicts data through its quartiles indicating the degree of dispersion and outliers located within \pm 1.5 of extreme quartiles. The term base scenarios refers to two conducted analyses described in Table II as scenarios one and two, which present the situation where PV installations and EVs are connected to the grid in addition to the households' consumption. Fig. 5 illustrates current distribution at the most important nodes for the base scenarios. The blue box indicates $50 \%$ of simulation results within the covered range where the median is highlighted in red. Upper and lower quartiles, i.e. $25 \%$ of the data are located within the vertically extended black lines, the so-called "whiskers". Outliers which can be considered as the extreme cases are marked with red plus signs. Fig. 5 clearly shows that the network is more loaded during the winter week with the median current value of 106.2 A than during the spring week when the median current value is $29.4 \mathrm{~A}$. Furthermore, node voltages are depicted in Fig. 6. With the connection of EVs, voltage profiles have significantly dropped with some values exceeding the $\pm 10 \%$ limit of nominal voltage, which clearly indicates the need for voltage support.

\section{B. Activation of RPC from PV installations (scenarios \#3 and \#4)}

In this section, the results for spring scenario of the modelled grid with added RPC from photovoltaic installations are reported. This analysis has been listed in Table II as scenario three, and differs from the base scenarios in terms of PV reactive power control capability. Similar scenario four is not of major interest here since PV production during the winter week is so small it leads to the same results as in scenario two. Accordingly, the potential of reactive power control from PV systems in scenario six is quite non-existent.

Current values for the given scenario increase when the RPC is activated (median value at 301 rises from 29.4 A to
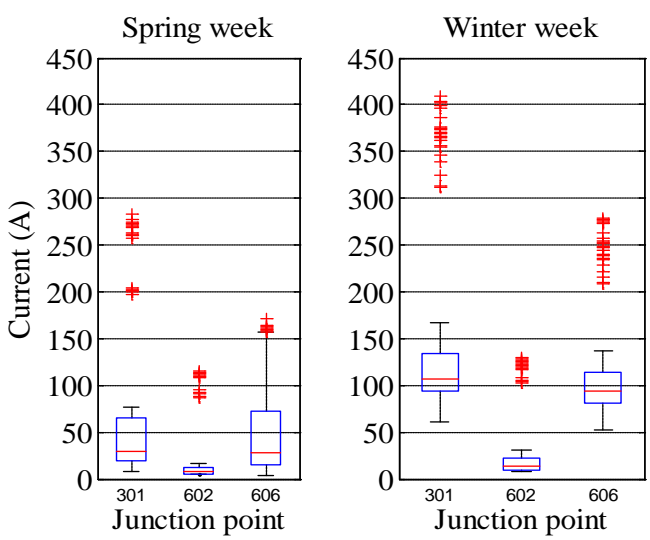

Fig. 5. Current comparison at selected junction points for the base scenarios

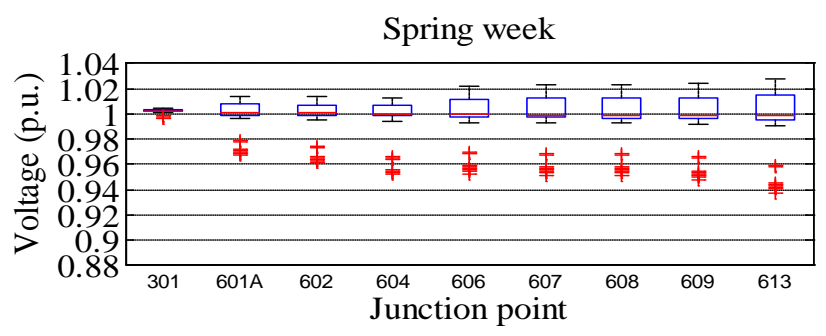

Winter week

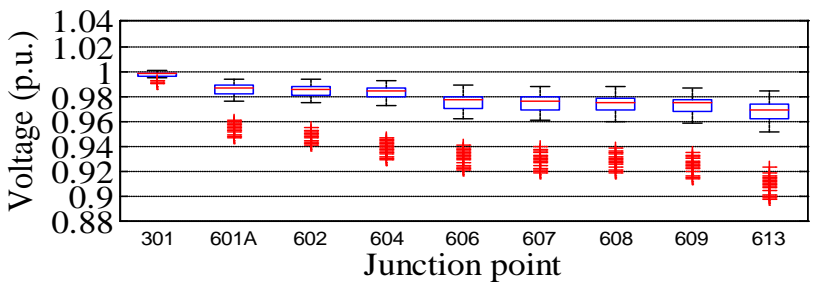

Fig. 6. Voltage comparison at selected junction points for the base scenarios

30.9 A, with maximum current increasing up to $11 \mathrm{~A}$ during the peak hours), which can be linked to reactive power providence resulting in excessive loading of the lines. Since grid losses are directly related to the current with quadratic dependence, excessive loading can cause high energy losses which will be reported in later subchapter. Fig. 7 and Table III present the voltages at specific nodes (e.g. at the beginning and the end of the segments) and show the RPC benefit in terms of voltage improvement. At the times of maximum PV production, the greatest benefit has been noticed for the furthest node of the line (node 613) where the voltage deviation has been decreased by $0.49 \%$.

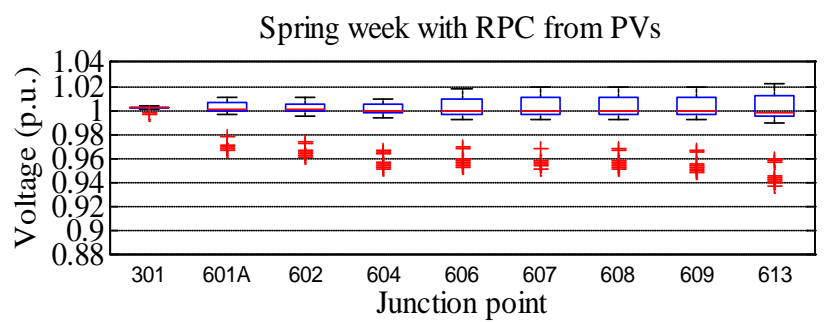

Fig. 7. Voltage profile at selected junction points after RPC activation from PVs for the spring week 
TABLE III

MAXIMUM VOLTAGES AT SELECTED JUNCTION POINTS BEFORE AND AFTER PV RPC ACTIVATION - SPRING WEEK

\begin{tabular}{|c|c|c|c|}
\hline Node & $\begin{array}{c}\text { Maximum voltage } \\
\text { without RPC (p.u.) }\end{array}$ & $\begin{array}{c}\text { Maximum voltage } \\
\text { with RPC (p.u.) }\end{array}$ & $\begin{array}{c}\text { Relative voltage } \\
\text { decrease (\%) }\end{array}$ \\
\hline 301 & 1.0052 & 1.0044 & 0.08 \\
\hline $601 \mathrm{~A}$ & 1.0137 & 1.0106 & 0.31 \\
\hline 602 & 1.0134 & 1.0103 & 0.31 \\
\hline 604 & 1.0130 & 1.0098 & 0.32 \\
\hline 606 & 1.0222 & 1.0181 & 0.40 \\
\hline 607 & 1.0235 & 1.0192 & 0.42 \\
\hline 608 & 1.0236 & 1.0193 & 0.42 \\
\hline 609 & 1.0244 & 1.0199 & 0.44 \\
\hline 613 & 1.0275 & 1.0225 & 0.49 \\
\hline
\end{tabular}

\section{Activation of RPC from EVs (scenarios \#5 and \#6)}

This section reports results for the scenarios when the RPC capability from EVs has been activated in addition to RPC from PV installations. These scenarios refer to scenarios five and six according to Table II. During the spring week, voltage support comes from two sources while there is only EV voltage support during the winter week due to small PV production as mentioned before. As the EV and PV times don't coincide and the spring scenario doesn't differ from the winter one in terms of peak hours, the focus point will be on the winter week when the loading is higher.

Fig. 8 compares current distribution at selected junction points before and after RPC activation for the winter week. It is interesting to observe how the maximum current at 301 in the case with activated EV reactive power control is lower
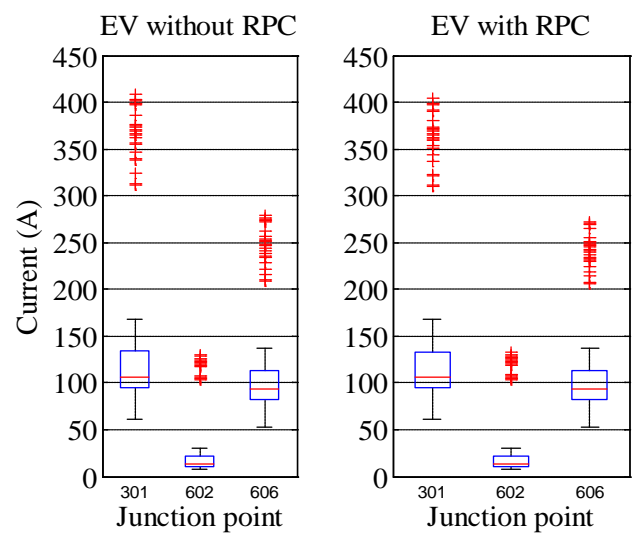

Fig. 8. Current comparison at selected junction points for the winter scenarios with and without EV RPC

Winter week with RPC from EV

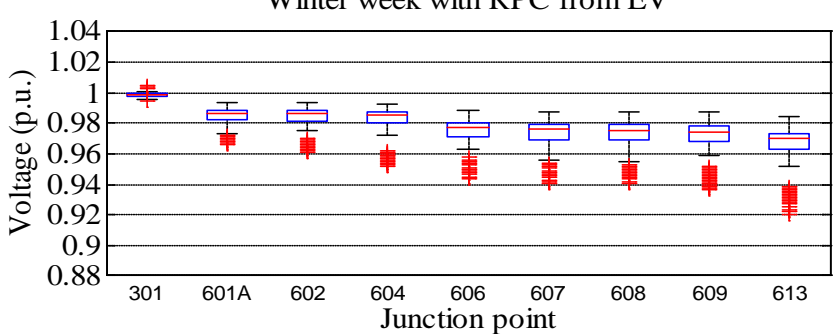

Fig. 9. Voltages at selected junction points after RPC activation from EVs for the winter week than the one without (value falls from 408.9 A to 403.9 A). The reason lies in the fact EVs first consume already existing reactive power in the grid and then continues the provide voltage support through extra reactive power consumption. This leads to overall smaller cable loading and energy losses. In addition to lowering current values at peak times, the EVs provide considerable voltage support comparing to the base winter scenario, especially for the end-line nodes, shown in Fig. 9. Minimum voltages for the winter week before and after EV reactive power control activation are presented in Table IV. It is clearly shown how RPC is crucial in peak times as it increases overall voltages and puts the end-line voltages back well within the $\pm 10 \%$ limit.

TABLE IV

MINIMUM VOLTAGES AT SELECTED JUNCTION POINTS BEFORE AND AFTER EV RPC ACTIVATION - WINTER WEEK

\begin{tabular}{|c|c|c|c|}
\hline Node & $\begin{array}{c}\text { Minimum voltage } \\
\text { without RPC (p.u.) }\end{array}$ & $\begin{array}{c}\text { Minimum voltage } \\
\text { with RPC (p.u.) }\end{array}$ & $\begin{array}{c}\text { Relative voltage } \\
\text { increase (\%) }\end{array}$ \\
\hline 301 & 0.9898 & 0.9947 & 0.50 \\
\hline $601 \mathrm{~A}$ & 0.9475 & 0.9659 & 1.94 \\
\hline 602 & 0.9410 & 0.9607 & 2.09 \\
\hline 604 & 0.9293 & 0.9518 & 2.42 \\
\hline 606 & 0.9219 & 0.9433 & 2.32 \\
\hline 607 & 0.9196 & 0.9411 & 2.34 \\
\hline 608 & 0.9186 & 0.9403 & 2.36 \\
\hline 609 & 0.9142 & 0.9366 & 2.45 \\
\hline 613 & 0.8978 & 0.9205 & 2.53 \\
\hline
\end{tabular}

\section{Results overview}

Fig. 10 presents energy flows at the substation level for the presented scenarios. To maintain the figure clarity, active and reactive power for the base scenarios are represented with solid lines, and reactive power when all voltage support is activated with the dashed line. In the case of RPC only from PVs, there would merely be no reactive power consumption in the evening peak hours. Total active and reactive power
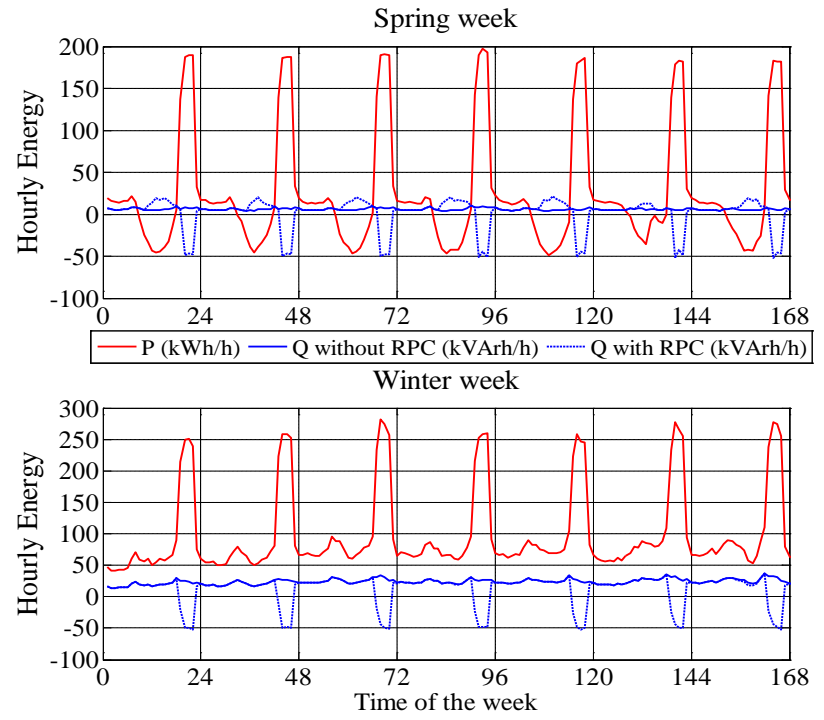

Fig. 10. Power profiles at the substation level for observed weeks 
TABLE V

RESULT OVERVIEW FOR PRESENTED SCENARIOS

\begin{tabular}{|c|c|c|c|c|c|c|c|c|}
\hline Scenario & Season & $\begin{array}{c}\text { PV } \\
\text { RPC }\end{array}$ & $\begin{array}{l}\mathrm{EV} \\
\mathrm{RPC}\end{array}$ & $\begin{array}{c}\text { Total absolute } \\
\text { active energy } \\
(\mathrm{kWh})\end{array}$ & $\begin{array}{c}\text { Total absolute } \\
\text { reactive energy } \\
(\mathrm{kVArh})\end{array}$ & $\begin{array}{l}\text { Active losses } \\
(\mathrm{kWh})\end{array}$ & $\begin{array}{c}\text { Ratio of active losses } \\
\text { and total active } \\
\text { energy }(\%) \\
\end{array}$ & $\begin{array}{c}\text { Ratio of active losses } \\
\text { and total apparent } \\
\text { energy (\%) }\end{array}$ \\
\hline 1 & spring & - & - & 7885.4 & 1007.1 & 242.4 & 3.07 & 3.01 \\
\hline 2 & winter & - & - & 16881.2 & 4032.3 & 689.8 & 4.08 & 3.95 \\
\hline 3 & spring & $\mathrm{X}$ & - & 7889.6 & 1436.6 & 245.7 & 3.12 & 3.01 \\
\hline 4 & winter & $\mathrm{X}$ & - & 16881.2 & 4032.3 & 689.6 & 4.08 & 3.95 \\
\hline 5 & spring & $\mathrm{X}$ & $X$ & 7896.7 & 2279.5 & 253.7 & 3.21 & 3.07 \\
\hline 6 & winter & $\mathrm{X}$ & $\mathrm{X}$ & 16753.8 & 4376.3 & 677.5 & 4.04 & 3.90 \\
\hline
\end{tabular}

refer to values at the substation level at each point of time where positive values mean import and negative values export to the grid.

To address the issue of energy losses due to excessive loading, Table $\mathrm{V}$ compares losses in absolute and relative values as well as the ratio of active losses and total apparent energy. It is clear from the table that active losses throughout all spring scenarios do not change significantly and amount to around 3\%. Similarly, during the winter scenarios, the losses come to around $4 \%$ with maximum deviation up to $12 \mathrm{kWh} / \mathrm{h}$ during the day. The ratio of active losses and total apparent energy also changes due to different amounts of reactive energy in the grid. However, these changes are not substantial leading to the conclusion that RPC activation does not influence the losses much even when doubling total reactive energy in the grid. On the contrary, the observed ratio in scenario six is somewhat lower due to consuming already existing reactive power in the network during the peak hours.

\section{CONCLUSION}

PV and EV employment will greatly affect modern distribution networks leading to additional requirements concerning voltage support to reduce the negative impacts and increase potential benefits. The case study presented in this work shows that RPC implementation from both PVs and EVs in a real Danish low voltage network positively effects the voltage conditions. Moreover, in a worst case scenario with all EVs charging at the same time, RPC is necessary to maintain the voltages within the allowable technical limits at the end of the lines. Since the voltage support is based on increased consumption of reactive power and consequently increased loading, this paper addressed changes in energy losses and cable loading. It can be concluded that the benefits regarding voltage improvement are greater than the side effects of additional cable loading for this low voltage network where the increase in median current is only $2 \mathrm{~A}$. Furthermore, the energy losses are not notably increased, but are in some cases even somewhat lower due to consumption of already existing reactive power in the network. For the analysed feeder, voltage support in the form of reactive power control is relevant for maintain the voltages within technical limits when integrating larger amount of EVs.
Although not addressed in this work, unbalanced phases might be limiting factor for EV and PV integration since most of them are connected to a single phase. This model will be extended for further research with unbalanced loading and different EV connections to gain insight into network conditions when providing unevenly distributed voltage support between the phases.

\section{REFERENCES}

[1] Y. G. Rebours, S. Member, D. S. Kirschen and M. Trotignon, “A Survey of Frequency and Voltage Control Ancillary Services - Part I : Technical Features,” Power Systems, IEEE Transcation on, vol. 22, no. 1, pp. 350-357, 2007.

[2] K. Knezovic and S. Krajcar, "Modelling and Simulating the Impact of a Small Solar Plant to the Low-Voltage Network,” EUROCON, 2013 IEEE , pp.1270,1277, 2013

[3] E. Pasca, G. Petretto, S. Grillo, M. Marinelli and F. Silvestro, "Characterization of wind and solar generation and their influence on distribution network performances,” Universities Power Engineering Conference (UPEC), pp.1-6, 2009.

[4] Y. Ueda, K. Kurokawa, T. Tanabe, K. Kitamura and H. Sugihara, "Analysis Results of Output Power Loss Due to the Grid Voltage Rise in Grid-Connected Photovoltaic Power Generation Systems,” Industrial Electronics, IEEE Transaction on, vol. 55, no. 7, pp. 2744-2751, 2008.

[5] E. Demirok, S. Member, P. C. Gonz, K. H. B. Frederiksen, D. Sera, P. Rodriguez, S. Member and R. Teodorescu, "Local Reactive Power Control Methods for Overvoltage Prevention of Distributed Solar Inverters in Low-Voltage Grids,” Photovoltaics, IEEE Journal of, vol. 1, no. 2, pp. 174-182, 2011.

[6] Dansk Energi, "Scenarios for the deployment of electric vehicles," 2013. (available: http://www.danskenergi.dk/ /media/DE_MJE/ Analyser/Analyse05-Scenarier_for_udrulning_af_elbiler.ashx

[7] W. Kempton and J. Tomić, "Vehicle-to-grid power implementation: From stabilizing the grid to supporting large-scale renewable energy," Journal on Power Sources, vol. 144, pp. 280-294, 2005.

[8] C. Gouveia, C. L. Moreira, J. Abel, P. Lopes and D. Varajão, "Microgrid Service Restoration: The Role of Plugged-in Electric Vehicles,” Industrial Electronics Maazine, IEEE, vol. 7, no. 4, 2013.

[9] F. Marra, D. Sacchetti, A. B. Pedersen, P. B. Andersen, E. Larsen and C. Traholt, "Implementation of an Electric Vehicle Test Bed Controlled by a Virtual Power Plant for Contributing to Regulating Power reserves,” PES General Meeting, IEEE, pp. 1-7., 2012

[10] Energinet.dk, "Technical Regulation 3.2.1. for electricity generation facilities with a rated current of 16 A per phase or lower,” 2011.

[11] Italian Technical Standard - CEI 0-21, "Reference technical rules for the connection of active and passive users to the LV electrical Utilities," June 2012. (available: http://www.ceiweb.it/doc/norme/ 12333.pdf)

[12] F. Adinolfi, F. Baccino, M. Marinelli, S. Massucco and F. Silvestro, "Model of a Real Medium Voltage Distribution Network for Analysis of Distributed Generation Penetration in a SmartGrid Scenario,” 2012 3rd IEEE PES Innovative Smart Grid Technology Europe, pp. 1-7, 2012.

[13] P. Bach Andersen, "Intelligent Electric Vehicle Integration - Domain Interfaces and Supporting Informatics,” Ph.D. thesis dissertation, Technical University of Denmark, Aug. 2013. 